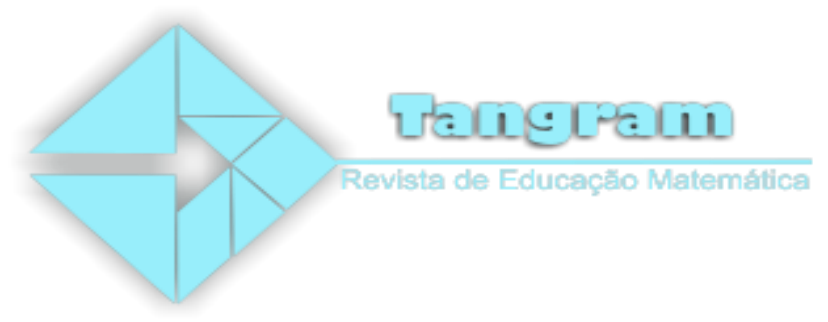

\title{
Aprimorando o desempenho de futuros profissionais em matemática financeira
}

\section{Improving the performance of future professionals in financial mathematics}

\author{
Geneci Alves de Sousa ${ }^{1}$ \\ Luciano Roberto Padilha de Andrade2 \\ Lilian Nasser ${ }^{3}$
}

Resumo:A aprendizagem Matemática, em especial de Matemática Financeira, ainda é um entrave para os alunos de diferentes níveis de ensino. Alunos de cursos superiores, como o de Ciências Contábeis, por exemplo, chegam ao curso superior com enormes lacunas na aprendizagem, oriundas da Educação Básica. Este trabalho apresenta os resultados de uma experiência desenvolvida em sala de aula, com alunos do Curso de Ciências Contábeis, de uma faculdade da Baixada Fluminense, Rio de Janeiro. O objetivo era verificar se a utilização de uma abordagem prática e visual, com representação num eixo de setas facilitaria o processo de ensino e aprendizagem da Matemática Financeira. Por meio da metodologia de Análise de Erros (CURY, 2004; 2007), pode-se categorizar os erros encontrados em um Pré-teste e direcionar as atividades de aula de acordo com as dificuldades detectadas. Os resultados foram significativos, indicando aumentos em torno de $85 \%$ no desempenho entre o Pré e o Pós-teste.

Palavras-chave: Matemática Financeira; Abordagem Prática e Visual; Eixo das Setas.

\begin{abstract}
Mathematics learning, especially Financial Mathematics, is still an obstacle for students of different levels of education. Higher-level students, such as Accounting Sciences, for example, arrive with huge learning gaps formed from Basic Education. This work presents the results of an experience developed in classroom, with students from the Course of Accounting Sciences, from an University in the Baixada Fluminense, Rio de Janeiro. The objective was to verify if the use of a practical and visual approach, with representation in an arrow axis would facilitate the teaching and learning process of Financial Mathematics. Through the methodology of Error Analysis (CURY, 2004; 2007), it is possible to categorize the errors found in a Pre-test and direct the class activities,
\end{abstract}

\footnotetext{
${ }^{1}$ Graduado em Matemática pela Fundação Educacional Rosemar Pimentel (1995), com habilitação em Matemática, Desenho Geométrico e Física; Mestre em Educação Matemática pela Universidade Santa Úrsula (2003). Atualmente é professor da disciplina de Física da Secretaria Estadual de Educação do Rio de Janeiro, professor de Matemática na Secretaria Municipal de Educação do Rio de Janeiro

${ }^{2}$ Mestre em Educação Matemática - CETIQT/SENAI; Projeto Fundão UFRJ

${ }^{3}$ Possui graduação em Licenciatura e Bacharelado em Matemática pela Universidade Federal do Rio de Janeiro (1972), mestrado em Matemática pela Universidade Federal do Rio de Janeiro (1976) e doutorado em Educação Matemática - University of London (1992). Atualmente é pesquisadora do Projeto Fundão e do programa de mestrado em Ensino de Matemática, do Instituto
}

Tangram - Revista de Educação Matemática, Dourados - MS - v.2 n. 2, pp. 25 - 46 (2019) 


\section{Aprimorando o desempenho de futuros profissionais em matemática financeira}

according to the difficulties observed. The results indicate a significant increase of around $85 \%$ in the performance, between Pre and Post-test.

Keywords: Financial math; Practical and Visual Approach; Axis of Arrows.

\section{Introdução}

Quem nunca necessitou efetuar cálculos matemáticos, de ordem financeira, por mais simples que fossem? Cada vez mais a tecnologia permite que realizemos operações, de todo o tipo, via internet, fazendo com que as distâncias sejam reduzidas, aproximando empresas e/ou pessoas. Esse avanço tecnológico e suas aplicações no mercado financeiro, aliadas aos meios de comunicação, sejam eletrônicos ou não, fazem com que cidadãos desinformados financeiramente ou até mesmo profissionais de áreas administrativas ou contábeis, por exemplo, se tornem vulneráveis às ações de pessoas ou instituições não idôneas.

A Matemática procura estabelecer um vínculo entre o mundo real, a partir do momento em que busca prever situações através da construção de modelos, utilizando fórmulas, variáveis, conceitos, teoremas, proposições, etc. Tais "ferramentas", se assim pudermos chamá-las, auxiliam na formação de habilidades na resolução de problemas numéricos desses modelos. Assim, na formação do profissional contábil, esses modelos são de grande importância para a melhoria da formação e do aprimoramento profissional.

No mundo globalizado em que vivemos, ter uma Contabilidade consistente é fundamental para o crescimento, não só de empresas, como de países, já que, graças a ela, o controle de elementos ou recursos se tornam mais eficientes, bem como as suas otimizações.

Diante desse cenário, um profissional contábil bem formado é extremamente importante. Para que se possa atingir tal objetivo, o curso de graduação deve ser de alto nível, em especial, na sua formação matemática.

Entretanto, o que encontramos nos resultados de diversas pesquisas é o baixo rendimento quando o assunto envolve as disciplinas de cunho matemático, não só no Curso de Ciências Contábeis, como em outros dessa área, como Administração e Economia.

No Brasil, o domínio da Educação Financeira é bastante deficiente na passagem do Ensino Médio para o Superior, causando dificuldades que geram evasão e repetência. Os resultados do PISA (Programme for International Student Assessment) (OCDE 2015) constatam essa deficiência, já que o Brasil apresentou o pior resultado no nível de Educação Financeira de 15 países. Esse estudo consistiu de um teste aplicado em 2015 a estudantes com 15 anos e as notas foram estruturadas em 5 níveis de Educação Financeira. O ideal, Tangram - Revista de Educação Matemática, Dourados - MS - v.2 n. 2, pp. 25 - 46 (2019) 


\section{Aprimorando o desempenho de futuros profissionais em matemática financeira}

segundo a Organização para a Cooperação e Desenvolvimento Econômico (OCDE), é que os alunos de 15 anos devem atingir, no mínimo o nível 2, que corresponde a conhecimentos financeiros necessários para o exercício da cidadania. No caso do Brasil, $53 \%$ dos alunos ficaram abaixo do nível 2 e apenas 3\% atingiram o nível 5.

Então o problema que se coloca é: como formar um profissional realmente capaz, ou seja, como fazer com que o aluno do curso de Ciências Contábeis, que se apresenta com uma grande deficiência de esferas inferiores, possa ter um melhor rendimento durante o curso de graduação? Em especial, focamos a investigação em disciplinas de cunho matemático, particularmente na de Matemática Financeira.

Embora o foco deste trabalho seja em cursos da área de negócios, admitimos que as discussões e resultados também se aplicam a trabalhos focados na formação de professores que ensinam Matemática. No entanto, vale observar que, no ambiente de trabalho, os problemas enfrentados são, em geral, mais complexos, dependendo de diversos fatores que requerem uma tomada de decisão.

Queiroz e Barbosa (2015) analisaram os exercícios propostos em livros didáticos de Matemática Financeira, adotados em cursos superiores da área de negócios, com o objetivo de "estabelecer características de exercícios [...] que sinalizem possíveis fronteiras com situações do cotidiano e de ambientes de trabalho" (p. 4). Os pesquisadores distinguiram dois tipos de exercícios: aqueles que dependem apenas dos dados, e podem ser resolvidos pela aplicação de uma fórmula, e aqueles que envolvem tomada de decisão. Embora a exploração de exercícios deste segundo tipo seja fundamental na formação profissional, os pesquisadores observaram que

nos problemas de decisão observados nos livros, as formas de resolução consideram aspectos meramente financeiros e conduzem o leitor sempre a uma única resposta certa. Não observamos exercícios desse tipo que considerassem contextos ou situações pessoais, nem desenvolvessem análises sócio críticas. Desse modo, concluímos que os exercícios que envolvem processo decisório, que por sua natureza, podem possibilitar experiências mais próximas do cotidiano e de ambientes de trabalho, não são explorados em suas potencialidades.

(QUEIROZ \& BARBOSA, 2015, p. )

Desse modo, julgamos que é preciso cometer uma "insubordinação criativa", no sentido sugerido por D’Ambrósio e Lopes (2015), ao abordarmos em nossa proposta de pesquisa exercícios de Matemática Financeira que se destacam do que aparece nos livros Tangram - Revista de Educação Matemática, Dourados - MS - v.2 n. 2, pp. 25 - 46 (2019) 


\section{Aprimorando o desempenho de futuros profissionais em matemática financeira}

didáticos. Além de envolver tomada de decisão, os exercícios que utilizamos admitem diversos caminhos para chegar à resposta, levando em conta situações e contextos pessoais.

\section{A pesquisa}

O início da pesquisa se deu pela aplicação de um teste diagnóstico (Pré-teste) à turma de $2^{\circ}$ período, do curso de Ciências Contábeis, de uma instituição de Ensino Superior, do município de Belford Roxo, do estado do Rio de Janeiro. O objetivo do teste era determinar o nível de conhecimento inicial dos alunos matriculados na disciplina de Matemática Financeira. Após a aplicação desse teste, os resultados foram categorizados e analisados quanto aos tipos de erros cometidos por esses alunos.

A partir da identificação das principais dificuldades dos estudantes, que geravam obstáculos à aprendizagem, foi elaborada uma sequência didática de acordo com a ementa da disciplina, de modo que o conteúdo e os problemas fossem abordados de forma inovadora, visando à superação desses obstáculos.

O rendimento da turma foi verificado pela aplicação de um segundo teste, com as mesmas questões do inicial, onde nova análise foi realizada e comparada com os resultados obtidos inicialmente.

O perfil da turma é bem heterogêneo, composto por três tipos de alunos. Alguns oriundos das redes públicas municipais, estão há mais de 15 anos sem estudar (45\%). Outro grupo é composto de alunos formados há menos de 3 anos, também oriundos das redes públicas $(38 \%)$ e os demais, que são da rede particular ou rede pública (não pertencentes à de Belford Roxo), têm entre 3 e 15 anos de formados.

A maior parte dos alunos matriculados são trabalhadores em diversas áreas (98\%) e desenvolvem seus estudos no turno da noite. Estes dispõem de pouco tempo para se dedicar ao estudo das diferentes disciplinas do curso. A utilização de calculadoras, em sua maioria, era feita por máquinas de quatro operações e, aqueles que possuíam uma calculadora científica não exploravam adequadamente suas operações básicas ou os seus métodos de utilização. Dessa forma, as dificuldades apresentadas eram muito grandes e o ritmo de desenvolvimento das aulas, mais lento do que o normal.

O teste diagnóstico foi aplicado um mês após o início do período letivo. Isto ocorreu pelo fato de que o período de Carnaval ocasiona uma baixa frequência. Por isso, a aplicação foi postergada para o dia 07 de março. Nessas aulas iniciais, no total de três dias, com três

Tangram - Revista de Educação Matemática, Dourados - MS - v.2 n. 2, pp. 25 - 46 (2019) 


\section{Aprimorando o desempenho de futuros profissionais em matemática financeira}

tempos de 50 minutos em cada dia, foi trabalhado o conteúdo de porcentagem e da importância em se utilizar a forma decimal.

A partir do início do mês de março, a presença dos alunos foi mais consistente. Dessa forma, pode-se efetuar a $1^{\text {a }}$ aplicação do teste diagnóstico, que contou com 24 alunos, que tiveram 1 h e 20 minutos para resolverem cinco questões, sendo as duas primeiras de múltipla escolha e as outras três discursivas. Mesmo nas questões de múltipla escolha, os alunos foram incentivados a registrar o raciocínio e os cálculos empregados nas resoluções.

Para a discussão e análise dos resultados, a amostra foi reduzida aos 24 alunos que responderam às duas aplicações do teste, e que assistiram à sequência didática apresentada à turma.

A seguir, descrevemos as questões do teste diagnóstico, com seus objetivos.

Primeira questão: Uma pessoa comprou um veículo seminovo, com um desconto de $20 \%$. Considerando que o valor pago pelo veículo foi $\mathrm{R} \$ 15.600,00$, já com o desconto, o valor economizado com esse desconto foi de:

(A) $\mathrm{R} \$ 2$ 000,00. (B) $\mathrm{R} \$ 3.120,00$. (C) $\mathrm{R} \$ 3$ 900,00. (D) $\mathrm{R} \$ 3$ 950,00. (E) $\mathrm{R} \$ 7$ 200,00.

Objetivo: Verificar se o aluno seria capaz de, a partir de um valor que sofreu um desconto, retornar ao valor principal e determinar qual foi o desconto. A resposta $\mathrm{R} \$ 3$ 900,00 representa que o aluno identificou corretamente o valor do desconto. O principal erro dos alunos nessa questão consistiu em calcular $20 \%$ do valor apresentado. Neste caso, nem era necessário achar o valor principal. Bastava observar que o valor final corresponde a 0,8 do valor inicial e, portanto, o desconto de 0,20 do valor principal corresponde à quarta parte do valor pago pelo veículo.

Segunda questão: O dono de uma loja, não conhecedor de Matemática Financeira, aumentou o preço original de um produto em $10 \%$. Uma cliente antiga comprou esse produto cujo preço foi reajustado. Para manter uma boa política com a clientela, o lojista deu um desconto de $20 \%$ sobre o preço reajustado, então, relativamente ao preço original, o preço final do produto será:

(A) $10 \%$ inferior. (B) $12 \%$ inferior (C) $18 \%$ inferior. (D) $30 \%$ superior. (E) $88 \%$ superior.

Objetivo: Verificar se o aluno seria capaz de realizar o cálculo envolvendo um aumento e um desconto sucessivos. A resposta correta de que o preço final ficará $12 \%$

Tangram - Revista de Educação Matemática, Dourados - MS - v.2 n. 2, pp. 25 - 46 (2019) 


\section{Aprimorando o desempenho de futuros profissionais em matemática financeira}

inferior representa que o aluno identificou o aumento e o desconto sucessivos e desenvolveu corretamente os cálculos.

Terceira questão: Uma prática muito comum entre lojistas, quando programam uma liquidação, é aumentar o valor da mercadoria antes do início da promoção e, logo após o término da mesma, retornam ao preço original, ou seja, ao valor da mercadoria antes da liquidação. Vamos considerar que, em uma rede de lojas, um certo produto é vendido a $\mathrm{R} \$$ 150,00 e, com o início da liquidação, sofreu um acréscimo de 20\%. Após o término, nem todo o estoque foi vendido e a gestão da rede resolveu abater o preço em $25 \%$.

a) Qual o valor do produto após o fim da liquidação?

b) A empresa efetuou o cálculo correto? Porque?

c) Considerando que não tenha concordado com o cálculo da empresa, como deveria ser feito?

O objetivo do item (a) era verificar se o aluno seria capaz de realizar o cálculo envolvendo um aumento e um desconto sucessivos sem a visualização de possíveis respostas (opções). $\mathrm{O}$ aluno que apresentou a resposta $\mathrm{R} \$ 135,00$ identificou o aumento e o desconto sucessivos e desenvolveu corretamente os cálculos. No item (b), o objetivo era verificar o poder de argumentação do aluno a partir dos resultados obtidos no item (a). A resposta "Não" para a primeira parte da pergunta era a esperada e, para a segunda parte, que da forma que foi calculado o valor final ficaria inferior ao valor inicial. $\mathrm{O}$ objetivo do item (c) era verificar se o aluno era capaz de determinar a taxa correta de desconto para que o valor da mercadoria, após o aumento de $20 \%$, retornasse ao seu valor original. O valor aproximado de $17 \%$ para essa taxa representa que o aluno resolveu corretamente este item.

Quarta questão: O dono da quitanda do meu bairro aumentou todos os preços, no mês de janeiro, em 7\%. Achando que os valores não ficaram de acordo com suas expectativas, aumentou novamente todos os preços, em 12\%, dez dias após o primeiro aumento.

a) De quantos por cento foi o aumento?

b) Se um certo produto, antes dos aumentos, custava $R \$ 12,50$, quanto passou a custar após o segundo aumento?

O objetivo do item (a) era verificar se o aluno seria capaz de realizar o cálculo envolvendo dois aumentos sucessivos sem a visualização de possíveis respostas (opções). A resposta 19,84\% Tangram - Revista de Educação Matemática, Dourados - MS - v.2 n. 2, pp. 25 - 46 (2019) 


\section{Aprimorando o desempenho de futuros profissionais em matemática financeira}

representa que o aluno identificou os dois aumentos e desenvolveu corretamente os cálculos. No item (b), o objetivo era verificar se, a partir da taxa encontrada no item "a", o aluno saberia aplicá-la para determinar o valor do produto com aumento. $\mathrm{O}$ valor de $\mathrm{R} \$ 14,98$ representa que o aluno aplicou corretamente a taxa, encontrando o valor com aumento.

Quinta questão: Jussara ganha $15 \%$ a mais que João. No mês de março Jussara será promovida e receberá um aumento de $20 \%$. Considerando o novo salário de Jussara, quantos por cento ela ganhará a mais que João?

Nesta questão, o objetivo era verificar se o aluno seria capaz de realizar uma comparação dos salários de Jussara e João, sem conhecer os seus valores, ou seja, utilizando-se apenas dos fatores de aumento. O valor de 38\% representa que o aluno efetuou corretamente os cálculos e, posteriormente, a comparação.

\section{Desenvolvimento pedagógico}

Durante dois meses, de 07 de março (data da primeira aplicação do teste diagnóstico) até o dia 09 de maio (data da segunda aplicação), foram realizados nove encontros (cada encontro com duração de $2 \mathrm{~h}$ e $40 \mathrm{~min}$ ), sempre às quartas-feiras.

Nesses encontros foram desenvolvidas questões que pudessem motivar os alunos e fazer com que compreendessem os possíveis erros cometidos nas respostas do teste diagnóstico.

Vamos descrever a sequência didática, baseada na proposta divulgada pelo grupo do Projeto Fundão em Nasser (2010), exemplificando algumas questões desenvolvidas em sala de aula.

Na resolução de exercícios de porcentagem, foi estimulado o uso da notação decimal, já que alguns exercícios podem ser resolvidos mais facilmente com essa notação, evitando os cálculos apenas pela regra de três.

Por exemplo, para saber o novo valor de uma certa mercadoria que sofreu um acréscimo de $18 \%$, basta multiplicar o preço original $\mathrm{P}$ por 1,18 , já que: $P+18 \%$ de $P=(1+0,18) . P=$ 1,18.P.

O aluno deveria compreender que, de um modo geral, para calcular o valor após um aumento de uma taxa i (na notação decimal), basta multiplicar o valor original pelo fator $(1+i)$, e no caso de um desconto, multiplica-se por $(1-i)$.

A utilização da porcentagem como fator facilita o seu trato com a calculadora, na resolução dos problemas, o que é recomendado, inclusive pelos Parâmetros Curriculares Nacionais.

Tangram - Revista de Educação Matemática, Dourados - MS - v.2 n. 2, pp. 25 - 46 (2019) 


\section{Aprimorando o desempenho de futuros profissionais em matemática financeira}

No caso em que se deseja obter o valor final de um certo produto, após ter sofrido acréscimos ou descontos sucessivos, a notação decimal deve ser usada para multiplicar (e não para somar) as taxas.

A utilização do eixo das setas foi estimulada entre os alunos, que inicialmente, questionavam a sua utilização, pois, como se trata de uma mudança de comportamento, oferecem certa resistência. Isto deve-se ao fato de que, como os exercícios iniciais, com datas de uma unidade de tempo, podem ser resolvidos, em sua maioria, pela utilização da regra de três, há uma preferência por sua utilização. Este pensamento acaba mudando quando os exercícios vão se tornando mais complexos, ou seja, com datas diferentes de uma unidade de tempo.

Portanto, nossa sugestão é que a utilização do eixo das setas, no momento inicial de trabalho com as turmas, seja estimulada ao máximo e, que tal observação, quanto ao emprego da regra de três, seja desestimulado e sinalizado que o seu uso será muito trabalhoso em exercícios mais complexos.

Vale ressaltar que do eixo das setas é formado por um eixo horizontal, que representa a linha do tempo, e setas verticais que indicam os valores em cada data. Entre uma seta e a seguinte são colocadas setas horizontais, indicando o fator multiplicado: $(1+i)$ ou $(1-i)$.

Exemplo: O exercício a seguir, aplicado por Novaes (2009), fez parte da sequência didática.

Bia pegou um empréstimo de $\mathrm{R} \$ 300,00$ a juros mensais de 5\%. Dois meses depois, Bia pagou $\mathrm{R} \$ 150,00$ e, um mês após esse pagamento liquidou seu débito. Qual o valor desse último pagamento?

Com a representação visual da resolução do exercício, com setas representando o valor das quantias em cada data, é possível entender a situação, sem a necessidade de procurar fórmulas. Transferindo as quantias para uma mesma data, pode-se somar e/ou subtraí-las de acordo com a situação.

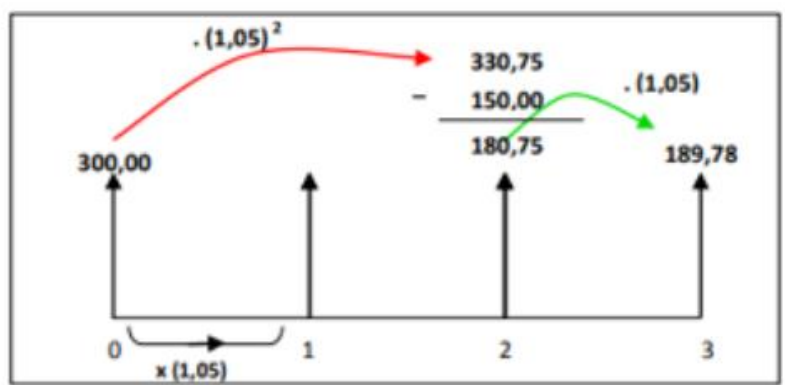

Figura 1-Resolução utilizando animação do PowerPoint.

Tangram - Revista de Educação Matemática, Dourados - MS - v.2 n. 2, pp. 25 - 46 (2019) 


\section{Aprimorando o desempenho de futuros profissionais em matemática financeira}

Apesar de poder parecer uma resolução complicada, a utilização do eixo das setas, apresentada inicialmente por Morgado et al (2005), facilita a compreensão e manuseio pelos alunos, sem a necessidade de memorizar fórmulas.

Com esse tipo de atividade buscou-se que o aluno pudesse compreender a variação do dinheiro no tempo. E que não se pode somar ou subtrair valor em datas distintas.

Em geral, a dificuldade apresentada pelos alunos foi a utilização do fator $(1+\mathrm{i})$ em dois meses consecutivos e o fato da subtração do valor que foi pago dois meses após a contratação do empréstimo. A existência de outras formas de respostas também foi incentivada demonstrando a facilidade que o eixo das setas permite, como:

$300-\frac{150}{1,05^{2}}=\frac{P}{1,05^{3}}$, trazendo as quantias para a data da contratação do empréstimo.

$300.1,05^{2}-150=\frac{P}{1,05}$, comparando as quantias na data do primeiro pagamento.

Outro exemplo trabalhado em aula foi o que segue:

Numa reunião de condomínio, foi aprovado um acréscimo de 10\%, em duas parcelas, sendo $5 \%$ de imediato, e o restante, 6 meses depois. Qual deve ser a taxa de aumento da $2^{\text {a }}$ parcela? (NASSER, 2010, p.23)

Nesse exemplo, grande parte dos alunos concluiu, equivocadamente, que a segunda parcela do aumento deve ser de 5\%, ou seja, sendo o primeiro aumento de 5\%, o segundo deveria ser o seu complementar, $10 \%-5 \%=5 \%$. Mas esse fator acarretaria um aumento superior a $10 \%$.

A resolução dessa atividade está representada na figura 2 a seguir.

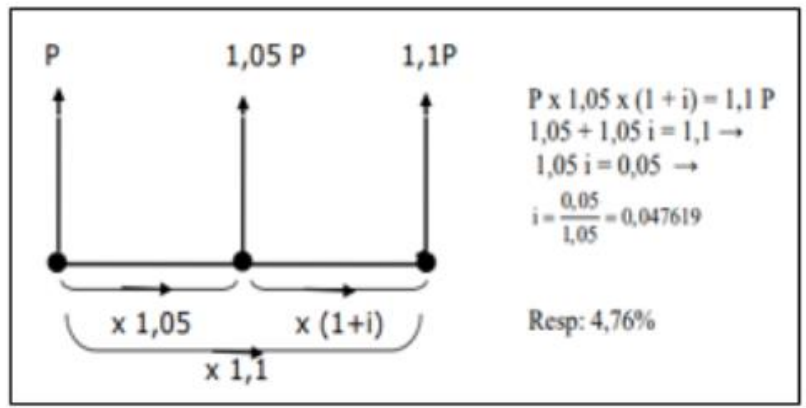

Figura 2-Fonte: NASSER (2010)

Tangram - Revista de Educação Matemática, Dourados - MS - v.2 n. 2, pp. 25 - 46 (2019) 


\section{Aprimorando o desempenho de futuros profissionais em matemática financeira}

Determinar o valor da taxa incidente sobre um aumento (ou desconto) foi outro modelo de questão desenvolvida em sala de aula, para auxiliar no desenvolvimento da habilidade de resolução de problemas de Matemática Financeira.

Vale comentar o seguinte exercício utilizado na sequência didática, encontrado em Nasser (2010, p. 26): Em um ano, o preço de uma mercadoria triplicou. Qual a porcentagem de aumento?

As respostas apresentadas pelos alunos indicavam que, em sua maioria, haviam atribuído um valor fictício de $\mathrm{R} \$ 100,00$ para o preço e, multiplicado por três, tendo em vista que o enunciado indicava a ocorrência do "triplo", encontravam R \$300,00. Dessa forma, associavam o valor da taxa a $300 \%$.

A resolução, também incentivada a usar o eixo das setas, segue na figura 3. Vale destacar a dificuldade na compreensão do valor encontrado, no cálculo, da taxa i sendo igual a 2 , ao ser convertido na representação percentual de $200 \%$

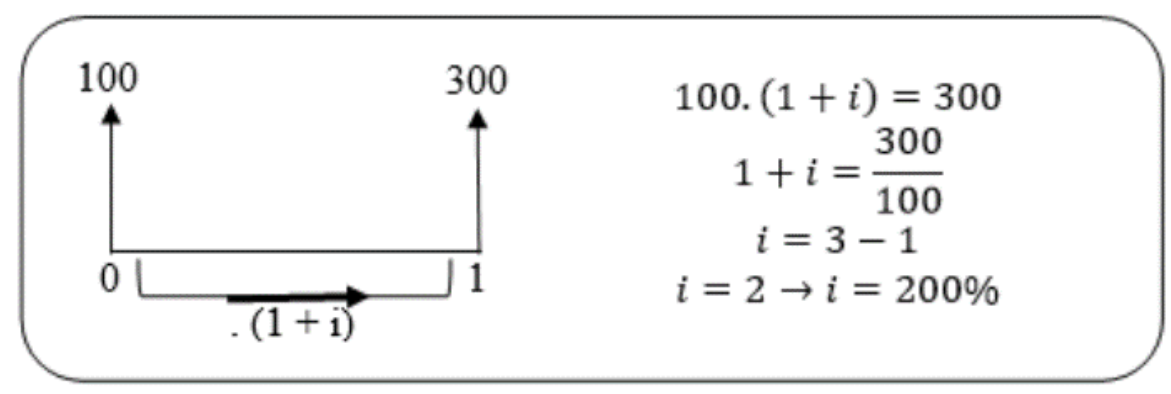

Figura 3-Resolução da questão desenvolvida em sala de aula

De um modo geral, com as resoluções das atividades propostas ao longo das aulas, procurouse fazer com que o aluno:

$\checkmark$ compreendesse que o uso da porcentagem como fator, na notação decimal, facilitava o trato com a calculadora e, consequentemente, na resolução da atividade e que, para encontrar um valor com acréscimo de i\% (na notação decimal), multiplica-se a quantia original por $(1+i)$ e se for desconto de i $\%$, multiplica-se a quantia original por $(1-i)$;

$\checkmark$ representasse uma situação-problema através do eixo das setas e pudesse realizar a transposição dos valores para uma mesma data, de modo que, pudesse ser comparados e/ou somados;

Tangram - Revista de Educação Matemática, Dourados - MS - v.2 n. 2, pp. 25 - 46 (2019) 


\section{Aprimorando o desempenho de futuros profissionais em matemática financeira}

$\checkmark$ pudesse explorar a resolução de problemas práticos, do dia-a-dia dos cidadãos;

$\checkmark$ fosse motivado ao uso de calculadoras (não financeiras, no máximo científicas) e desencorajado ao uso de fórmulas;

$\checkmark$ integrasse com outros conteúdos como progressões e gráficos das funções afim e exponencial;

$\checkmark$ fosse capaz de analisar diversas estratégias para resolver um mesmo problema.

\section{Metodologia de Análise de Erros}

Para orientar a análise dos resultados optamos por adotar a metodologia de análise de erros, que tem sido utilizada em investigações sobre a aprendizagem de diversos conteúdos da Matemática, em todos os níveis de ensino. A identificação, análise e a categorização dos erros apresentados pelos estudantes, são utilizadas com o objetivo de identificar suas causas e possíveis obstáculos para a aprendizagem. Helena Cury, no Brasil, tem desenvolvido e divulgado essa linha de pesquisa. De acordo com essa pesquisadora,

a análise das respostas, além de ser uma metodologia de pesquisa, pode ser, também, enfocada como metodologia de ensino, se for empregada em sala de aula, como "trampolim de aprendizagem" (Borasi, 1985), partindo dos erros detectados e levando os alunos a questionar suas respostas, para construir o próprio conhecimento (CURY, 2007).

Em sua pesquisa Cury e Cassol (2004, p. 28) identificam três tipos de estudos enfocando a análise de erros. No primeiro tipo, os erros dos alunos são apenas identificados e classificados, sem a preocupação em buscar as causas dos erros ou em aproveitá-los para promover a aprendizagem. Essa preocupação aparece no segundo tipo de estudo, com ênfase no conteúdo. São enfocados os obstáculos inerentes à aprendizagem e o processo de ensino e aprendizagem dos conteúdos a que se referem as respostas analisadas. Já nos estudos do terceiro tipo, a ênfase desloca-se para as atividades propostas e na análise de suas soluções. Os erros são discutidos com base nos objetivos da investigação e nos pressupostos teóricos adotados.

Para proceder à análise, os erros cometidos serão agrupados de acordo com sua natureza, criando categorias. Esse método de pesquisa é recomendado por Fiorentini e Lorenzato (2009), quando afirmam que "a categorização significa um processo de classificação ou de organização de informações em categorias, isto é, em classes ou conjuntos que contenham elementos ou características comuns”. (p. 134).

\section{Resultados obtidos}

Tangram - Revista de Educação Matemática, Dourados - MS - v.2 n. 2, pp. 25 - 46 (2019) 


\section{Aprimorando o desempenho de futuros profissionais em matemática financeira}

Os gráficos apresentados a seguir fazem uma comparação dos resultados obtidos após as duas aplicações do teste diagnóstico, em março e em maio. Para auxiliar a análise dos resultados, os erros foram classificados, conforme as tabelas explicativas em cada questão.

Para cada questão é apresentado também um gráfico comparando o número de respostas correspondentes a cada categoria nas duas aplicações do teste.

Questão 1 - Uma pessoa comprou um veículo seminovo, com um desconto de $20 \%$. Considerando que o valor pago pelo veículo foi $\mathrm{R} \$ 15.600,00$, já com o desconto, o valor economizado com esse desconto foi de:

(A) $\mathrm{R} \$ 2$ 000,00. (B) $\mathrm{R} \$ 3.120,00$. (C) $\mathrm{R} \$ 3$ 900,00. (D) $\mathrm{R} \$ 3$ 950,00. E) $\mathrm{R} \$ 7200,00$.

A tabela 1 mostra a distribuição das respostas pelas categorias detectadas na questão 1 .

Tabela 1-Tabela com o quantitativo de respostas em cada categoria na questão 1.

\begin{tabular}{|l|l|c|c|}
\hline & Descrição & Pré-teste & Pós-teste \\
\hline I & $\begin{array}{l}\text { Considerou a multiplicação de 20.100=2000, como } \\
\text { solução. }\end{array}$ & 0 & 0 \\
\hline II & $\begin{array}{l}\text { Multiplicou 0,20.15600 = 3120, ou seja, calculou 20\%do } \\
\text { valor descontado (alternativa B) }\end{array}$ & 15 & 9 \\
\hline III & $\begin{array}{l}\text { Multiplicou 1,20 por 15 600 e, logo após, subtraiu de 15 } \\
600 .\end{array}$ & 0 & 0 \\
\hline IV & $\begin{array}{l}\text { Subtraiu 15 600 do valor 19 500. Porém, não justificou a } \\
\text { origem do valor 19 500. }\end{array}$ & 1 & 0 \\
\hline V & Em branco. & $\mathbf{2 4}$ & $\mathbf{2 4}$ \\
\hline VI & Acertou a questão, respondendo R\$3 900,00. (alternativa C) \\
\hline & Total & 7 & 13 \\
\hline
\end{tabular}

Nesse item, observamos uma concentração maior no erro de tipo II, que no nosso entendimento, é um erro muito comum entre pessoas que não possuem um conhecimento mínimo de matemática financeira. Tal erro também pode ser atribuído ao fato de o aluno se atentar apenas aos valores que aparecem no enunciado, sem realizar uma leitura adequada e compreender o que a questão pede de fato, calculando o valor do desconto sobre o preço reduzido, e não do valor inicial. O gráfico 1 ilustra os resultados da questão 1, comparando o número de respostas dadas em cada categoria nas duas aplicações do teste.

Tangram - Revista de Educação Matemática, Dourados - MS - v.2 n. 2, pp. 25 - 46 (2019) 


\section{Aprimorando o desempenho de futuros profissionais em matemática financeira}

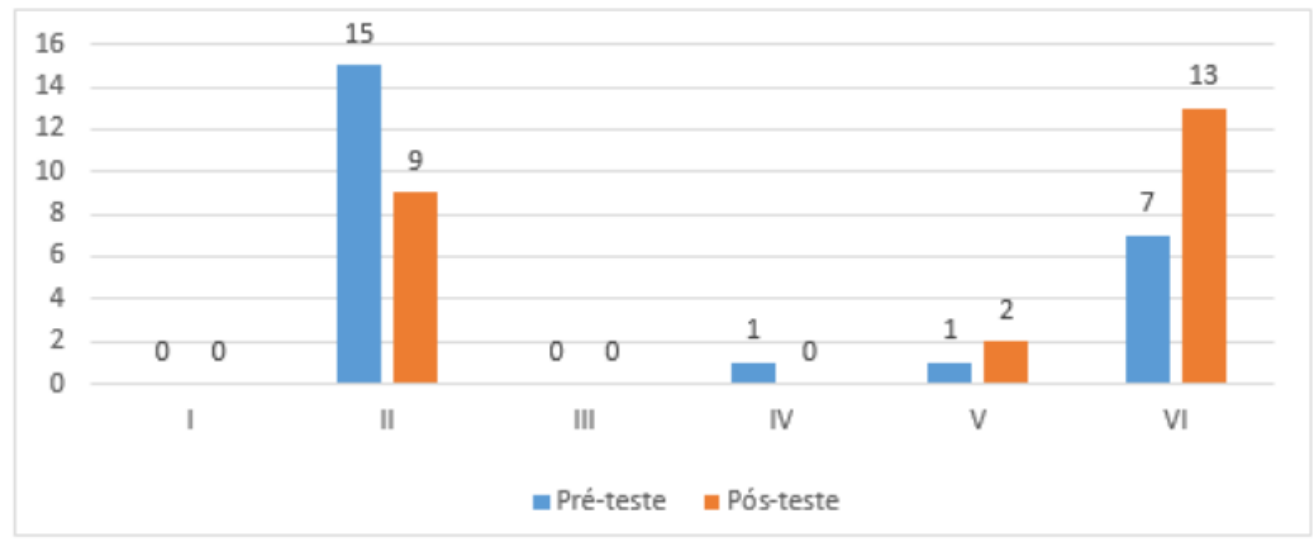

Gráfico 1-Concentração de respostas dos alunos nas categorias da questão 1.

O gráfico 1 mostra que, no pós-teste, houve o decréscimo de $40 \%$ no número de estudantes que cometeram erro do tipo II.

Questão 2 - O dono de uma loja, não conhecedor de matemática financeira, aumentou o preço original de um produto em $10 \%$. Uma cliente antiga comprou esse produto cujo o preço foi reajustado. Para manter uma boa política com a clientela, o lojista deu um desconto de $20 \%$ sobre o preço reajustado, então, relativamente ao preço original, o preço final do produto será:

(A) $10 \%$ inferior. (B) $12 \%$ inferior. (C)18\% inferior. (D)30\% superior. (E) $88 \%$ superior.

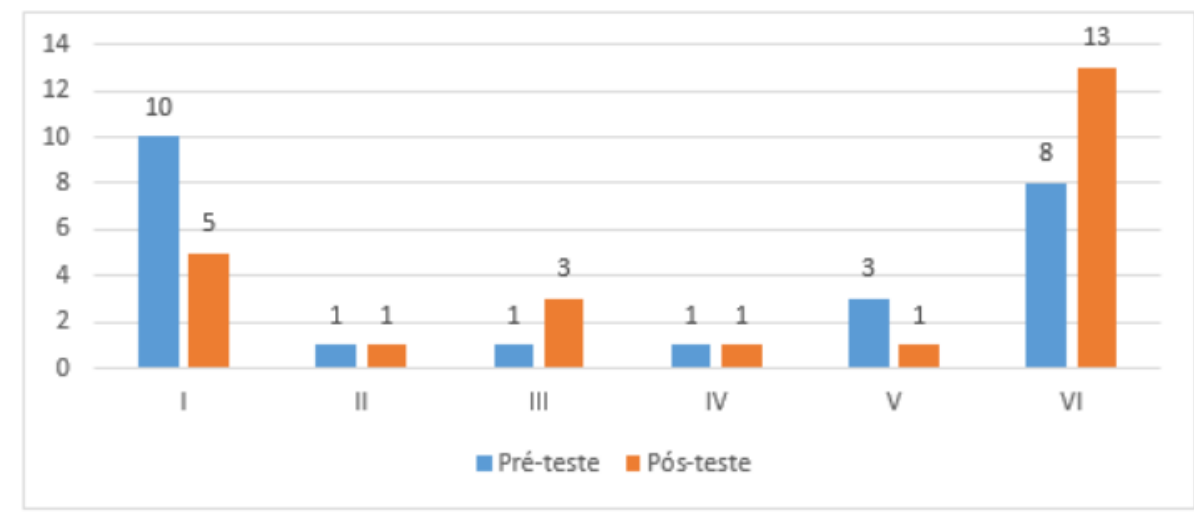

Gráfico 2-Concentração de respostas apresentadas pelos alunos nas categorias da questão 2.

Nessa questão, por se tratar de um assunto que foi amplamente discutido em sala de aula, onde se explicou que ocorrendo aumentos ou descontos sucessivos os fatores deveriam ser multiplicados e não somados ou subtraídos, esperávamos que os erros ocorridos na $1^{\mathrm{a}}$ aplicação não ocorressem na segunda ou que, pelo menos, ocorresse uma redução significativa.

Tangram - Revista de Educação Matemática, Dourados - MS - v.2 n. 2, pp. 25 - 46 (2019) 


\section{Aprimorando o desempenho de futuros profissionais em matemática financeira}

Tabela 2-Tabela com o quantitativo de respostas por categoria assinaladas na questão 2.

\begin{tabular}{|l|l|c|c|}
\hline & Descrição & Pré-teste & Pós-teste \\
\hline I & Efetuou a subtração de 20\% - 10\% = 10\%. (alternativa A) & 10 & 5 \\
\hline II & $\begin{array}{l}\text { Escreveu 0,1. }(1+i) \text { e colocou a resposta como 12\%. } \\
\text { Sem demonstrar como obteve o resultado. (alternativa B) }\end{array}$ & 1 & 1 \\
\hline III & Aplicou 1,1 $-0,8=0,3$, respondendo 30\%. (alternativa C) & 1 & 3 \\
\hline IV & $\begin{array}{l}\text { Aplicou 1,1x1,02 =1,122, 1,1 x 0,8 = 0,88, mas não } \\
\text { percebeu que o valor ficaria inferior. (Alternativa E) }\end{array}$ & 1 & 1 \\
\hline V & Em branco. & 3 & 1 \\
\hline VI & Acertou a questão (alternativa B) & 8 & 13 \\
\hline \multicolumn{2}{|c|}{ Total } & $\mathbf{2 4}$ & $\mathbf{2 4}$ \\
\hline
\end{tabular}

Apesar das reduções ocorridas, erros do tipo I e III repetiram-se. Olhando na frequência das aulas, os alunos que registraram tais erros, não eram infrequentes. Há registros de apenas uma falta para ambos. Vale o destaque para o erro III, que ao nosso entendimento é uma tentativa desesperada em encontrar o resultado a partir dos valores exibidos no texto. Por outro lado, o aluno que cometeu o erro 4 aplicou corretamente o produto dos fatores $1,1 \times 0,8=0,88$, mas concluiu que significava um aumento, e não a diferença de $12 \%$ a menos, no valor original.

Na questão 3, os itens serão analisados separadamente.

Questão 3 - Uma prática muito comum entre lojistas, quando programam uma liquidação, é aumentar o valor da mercadoria antes do início da promoção e, logo após o término da mesma, retornam ao preço original, ou seja, valor da mercadoria antes da liquidação. Vamos considerar que, em uma rede de lojas, um certo produto é vendido a $\mathrm{R} \$ 150,00$ e, com o início da liquidação, sofreu um acréscimo de $20 \%$. Após o término, nem todo o estoque foi vendido e a gestão da rede resolveu abater o preço em $25 \%$.

a) Qual o valor do produto após o fim da liquidação?

Tabela 3-Tabela com o quantitativo de respostas em cada categoria apresentadas à questão 3(a) .

\begin{tabular}{|l|l|c|c|}
\hline & Descrição & Pré-teste & Pós-teste \\
\hline I & $\begin{array}{l}\text { Efetuou a subtração } 25 \%-20 \% \text { e, logo após o } \\
\text { produto 0,05x150=7,50. }\end{array}$ & 4 & 3 \\
\hline II & Calculou 95\% de 150. & 6 & 2 \\
\hline III & $\begin{array}{l}\text { Calculou 20\% de 150 e o resultado subtraiu de } \\
150 .(0,20 \times 150=30 \text { e } 150-30=120) .\end{array}$ & 3 & 3 \\
\hline IV & $\begin{array}{l}\text { Efetuou corretamente a primeira parte do } \\
\text { cálculo. Porém, na segunda, calculou 25\% de } \\
180 .\end{array}$ & 1 & 2 \\
\hline V & Em branco. & 2 & 1 \\
\hline VI & Acertou a questão, respondendo R\$135,00. & 8 & $\mathbf{2 4}$ \\
\hline \multicolumn{1}{|c}{ Total } & $\mathbf{2 4}$ & 13 \\
\hline
\end{tabular}

Tangram - Revista de Educação Matemática, Dourados - MS - v.2 n. 2, pp. 25 - 46 (2019) 


\section{Aprimorando o desempenho de futuros profissionais em matemática financeira}

Observamos um aumento nos acertos. Entretanto, todos os erros ainda registraram ocorrência no pós-teste.

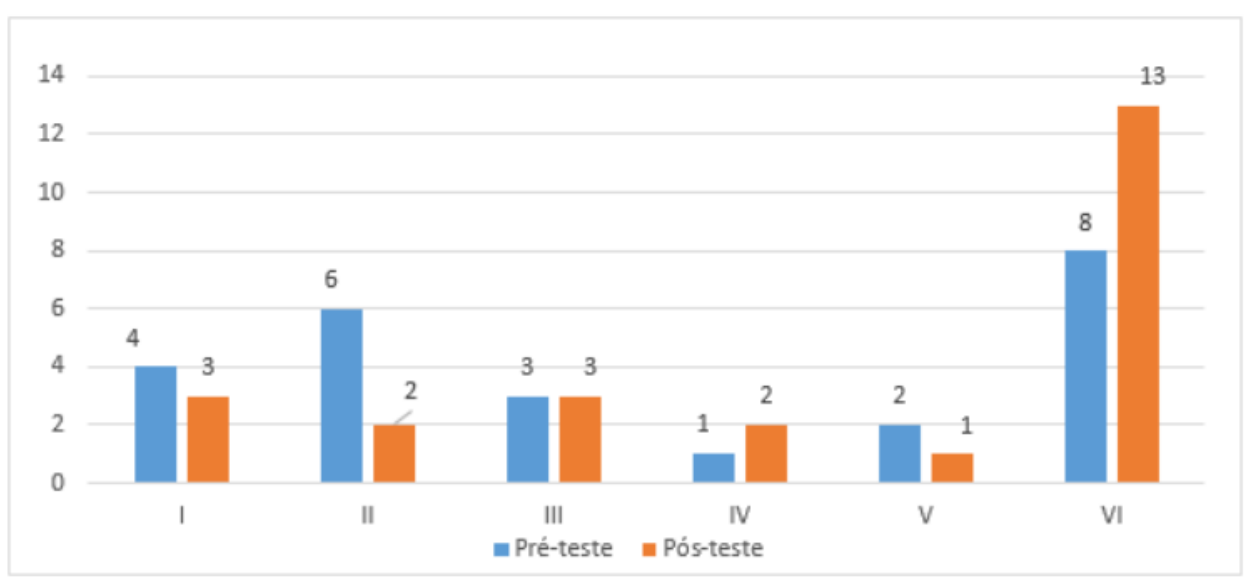

Gráfico 3-Concentração de respostas apresentadas pelos alunos nas categorias da questão 3(a).

Repete-se aqui a questão do aumento e desconto sucessivos citado no item anterior. Apesar das reduções, acreditamos que questões nessa linha devam ser mais exaustivamente trabalhadas para uma melhor compreensão.

b) A empresa efetuou o cálculo correto? Por que?

Como já foi comentado, o objetivo do item (b) era verificar o poder de argumentação do aluno a partir dos resultados obtidos no item (a). Não bastava perceber que o cálculo não estava correto. Era preciso perceber que o valor final ficaria inferior ao valor inicial, já que o produto $1,2 \mathrm{x}$ $0,75=0,9$ indica que o preço final ficou $10 \%$ menor. A tabela 4 indica a distribuição das respostas por categoria.

Tabela 4-Tabela com o quantitativo de respostas apresentadas à questão 3(b).

\begin{tabular}{|l|l|c|c|}
\hline & Descrição & Pré-teste & Pós-teste \\
\hline I & $\begin{array}{l}\text { Respondeu NÃO, mas, não justificou } \\
\text { ou justificou com erro. }\end{array}$ & 11 & 3 \\
\hline II & $\begin{array}{l}\text { Respondeu SIM, mas, justificou } \\
\text { errado. }\end{array}$ & 5 & 4 \\
\hline III & $\begin{array}{l}\text { Respondeu "DEPENDE" sem } \\
\text { justificaro porquê. }\end{array}$ & 1 & 0 \\
\hline IV & Em branco NÃO e justificou & 3 & 13 \\
\hline V & $\begin{array}{l}\text { Respondeu NÃO } \\
\text { corretamente. (Acertou a questão) }\end{array}$ & $\mathbf{2 4}$ & $\mathbf{2 4}$ \\
\hline \multicolumn{1}{|c|}{ Total } & \\
\hline
\end{tabular}

Tangram - Revista de Educação Matemática, Dourados - MS - v.2 n. 2, pp. 25 - 46 (2019) 


\section{Aprimorando o desempenho de futuros profissionais em matemática financeira}

As questões deixadas em branco nesse item, em ambas as aplicações, foram registradas pelos mesmos alunos, apesar de que, em outras questões, na mesma linha de desenvolvimento, não deixaram de responder, pelo contrário, acertaram as mesmas. Acreditamos que essa questão apresentou um maior grau de dificuldade por exigir que o aluno expressasse de forma textual a compreensão do cálculo executado. Tal dificuldade também foi registrada ao longo das aulas. Os alunos não estão habituados a resolver questões que exigem o registro textual do raciocínio de cálculo.

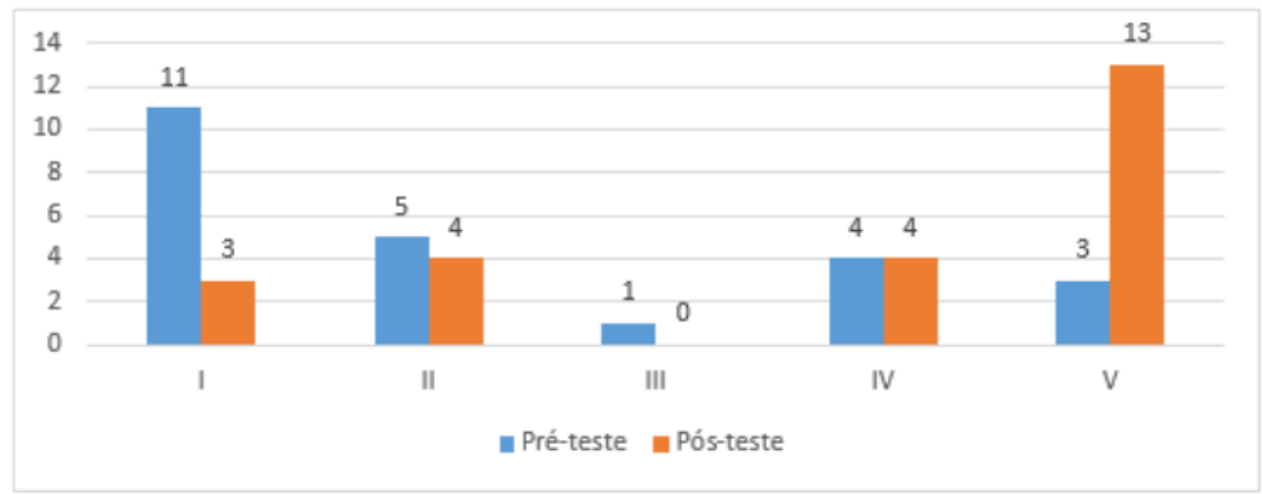

Gráfico 4-Concentração de respostas apresentadas pelos alunos nas categorias da questão 3(b).

Apesar desse comportamento, houve um aumento de $83 \%$ no índice de acertos nesse item da $3^{\mathrm{a}}$ questão.

c) Considerando que não tenha concordado com o cálculo da empresa, como deveria ser feito?

Novamente, as dificuldades se devem principalmente, à necessidade de explicar como deveria ser o cálculo correto.

Tangram - Revista de Educação Matemática, Dourados - MS - v.2 n. 2, pp. 25 - 46 (2019) 


\section{Aprimorando o desempenho de futuros profissionais em matemática financeira}

Tabela 5-Tabela com o quantitativo de respostas por categoria apresentadas à questão 3(c) ..

\begin{tabular}{|l|l|c|c|}
\hline & Descrição & $\begin{array}{c}\text { Pré- } \\
\text { teste }\end{array}$ & $\begin{array}{c}\text { Pós- } \\
\text { teste }\end{array}$ \\
\hline I & Reduzindo em 15\%, passando o valor para R\$ 150,00. & 1 & 3 \\
\hline II & $\begin{array}{l}\text { Ela deveria após o aumento, ter diminuído a porcentagem } \\
\text { sendo assim o produto iria ficar no final o valor normal } \\
\text { sem reajuste, para que não ocorresse prejuízo. }\end{array}$ & 1 & 1 \\
\hline III & $\begin{array}{l}\text { Resolveu através de fórmula } V_{f 1}=150 .(1-0,2)=120 \\
\text { e depois aplicou a fórmula } V_{f 2}=120 .(1-0,8)=150 .\end{array}$ & 1 & 1 \\
\hline IV & Aumento de 20\% e abatimento de 25\% & 1 & 1 \\
\hline V & $\begin{array}{l}\text { No mínimo, ter retornado ao valor de RS 150 (retirando o } \\
\text { acréscimo de 20\%) e não dando um desconto de 25\% sobre } \\
\text { o valor de liquidação. }\end{array}$ & 2 & 1 \\
\hline VI & $\begin{array}{l}\text { Teria que diminuir a mesma porcentagem que foi acrescida } \\
\text { no valor inicial. }\end{array}$ & 3 & 0 \\
\hline VII & Em branco & 2 & 4 \\
\hline VIII & Acertou, respondendo que o desconto deveria ser de $17 \%$. & 3 & 13 \\
\hline \multicolumn{2}{|c|}{ Total } & $\mathbf{2 4}$ \\
\hline
\end{tabular}

Para encontrar a resposta, era preciso encontrar o valor de i na expressão: $(1-\mathrm{i}) \times 1,2 \times 150=150 \Rightarrow(1-\mathrm{i}) \times 1,2=1 \Rightarrow 1,2 \mathrm{i}=0,2 \Rightarrow \mathrm{i}=0,1666$.

Portanto, a resposta correta seria aplicar um desconto aproximado de $17 \%$ após o término da liquidação.

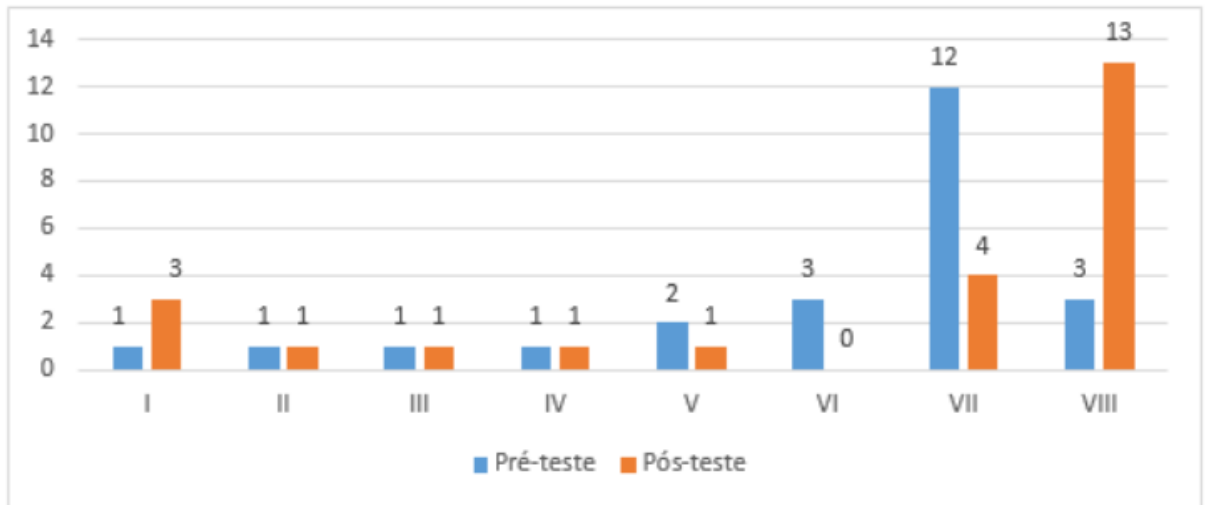

Gráfico 5-Concentração de respostas apresentadas pelos alunos nas categorias da questão 3(c).

Observamos uma grande migração dos alunos que, na $1^{\text {a }}$ aplicação, deixaram esse item em branco, acertando a questão no pós-teste. Entretanto, os erros registrados praticamente continuaram a ocorrer, com exceção do erro de tipo VI. Isso indica que os estudantes passaram a perceber que os fatores de acréscimo e desconto não devem ser somados. Aqui também vale o destaque mencionado no item, anterior quando foi comentada a dificuldade no registro textual.

Questão 4 - O dono da quitanda do meu bairro aumentou todos os preços, no mês de janeiro, em 7 $\%$. Achando que os valores não ficaram de acordo com suas expectativas, aumentou novamente todos os preços, em $12 \%$, dez dias após o primeiro aumento.

a) De quantos por cento foi o aumento?

Tangram - Revista de Educação Matemática, Dourados - MS - v.2 n. 2, pp. 25 - 46 (2019) 


\section{Aprimorando o desempenho de futuros profissionais em matemática financeira}

Observa-se que, de acordo com a tabela 6, o número de respostas corretas dobrou na segunda aplicação do teste.

Tabela 6-Tabela com o quantitativo de respostas por categoria apresentadas à questão 4 (a).

\begin{tabular}{|l|l|c|c|}
\hline & Descrição & Série 1 & Série 2 \\
\hline I & Somou 7\% com 12\%, respondendo 19\%. & 9 & 2 \\
\hline II & $\begin{array}{l}\text { Sem apresentar o cálculo, porém, } \\
\text { acertando o valor final }\end{array}$ & 2 & 2 \\
\hline III & $\begin{array}{l}\text { Considerou apenas o último reajuste } \\
(12 \%)\end{array}$ & 3 & 2 \\
\hline IV & Diminuiu 12\% de 7\% Respondendo 5\% & 1 & 1 \\
\hline V & Multiplicou 0,7 por 0,12 & 1 & 1 \\
\hline VI & Em branco questão, respondendo 19,84\% & 1 & 1 \\
\hline VII & Acertou a qual & $\mathbf{2 4}$ & 15 \\
\hline \multicolumn{1}{|c|}{ Total } & $\mathbf{2 4}$ \\
\hline
\end{tabular}

Vale ressaltar que os erros II, IV, V e VI foram registrados pelos mesmos alunos, não ocorrendo nenhuma evolução na aprendizagem desses 5 alunos.

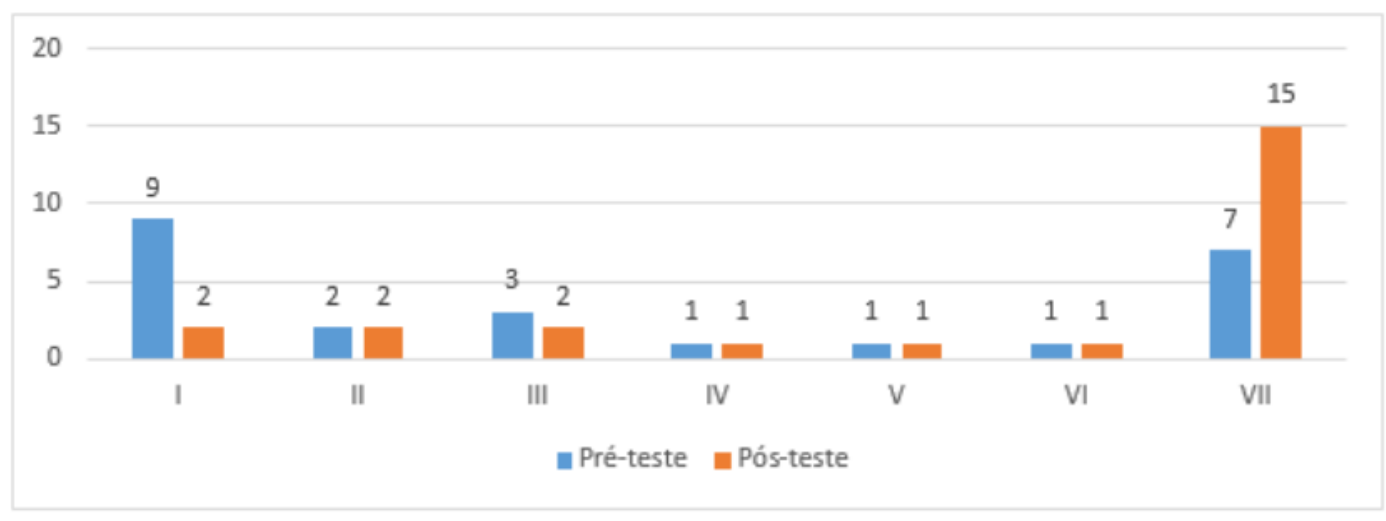

Gráfico 6-Concentração de respostas apresentadas pelos alunos nas categorias da questão 4(a).

No entanto, merece destaque o número de alunos que passaram a acertar a questão, praticamente abandonando o erro de tipo I (somar aumentos sucessivos), contribuindo na evolução de mais de $100 \%$ de acertos, da $1^{a}$ para a $2^{a}$ aplicação do teste.

b) Se um certo produto, antes dos aumentos, custava $R$ \$ 12,50, quanto passou a custar após o segundo aumento?

O número de acertos neste item foi igual ao do anterior, nas duas aplicações do teste, como mostra a tabela 7 .

Tangram - Revista de Educação Matemática, Dourados - MS - v.2 n. 2, pp. 25 - 46 (2019) 


\section{Aprimorando o desempenho de futuros profissionais em matemática financeira}

Tabela 7-Tabela com o quantitativo de respostas por categoria apresentadas à questão 4(b)

\begin{tabular}{|l|l|c|c|}
\hline & Descrição & Pré-teste & Pós-teste \\
\hline I & Utilizou 19\% para efetuar o cálculo. & 9 & 5 \\
\hline II & $\begin{array}{l}\text { Erro ao representar na forma decimal os percentuais 7\% e } \\
12 \% .\end{array}$ & 3 & 1 \\
\hline III & Erro na multiplicação de números na forma decimal. & 1 & 0 \\
\hline IV & Calculou apenas 12\% & 3 & 2 \\
\hline V & Em branco & 1 & 1 \\
\hline VI & Acertou a questão, respondendo RS 14,98. & 7 & 15 \\
\hline \multicolumn{2}{|c|}{ Total } & $\mathbf{2 4}$ & $\mathbf{2 4}$ \\
\hline
\end{tabular}

Pode-se observar uma redução em todos os tipos de erros, exceto nas respostas em branco, registradas por alunos diferentes. A questão aborda o mesmo tipo de assunto que já citamos anteriormente (aumento e desconto sucessivos). Por ser tratar de uma questão mais operacional, não registramos tanta dificuldade na resolução quanto àquela que exigia o registro textual. Isso mostra que, em geral, o aluno aprende a resolver, mas, não sabe detalhar a sua resolução, textualmente.

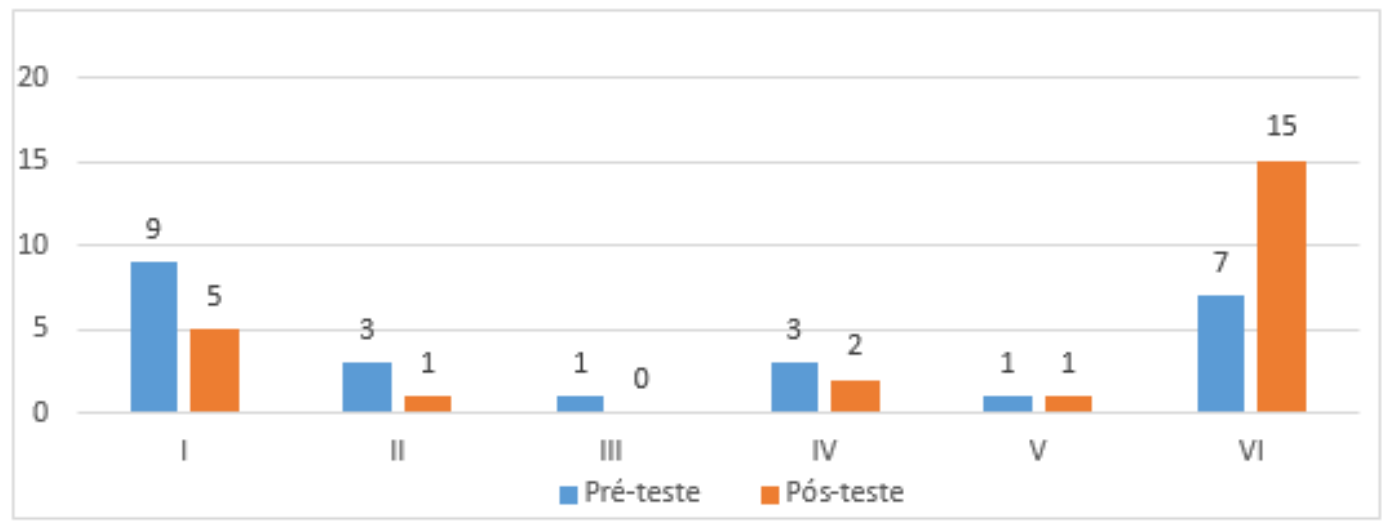

Gráfico 7-Concentração de respostas apresentadas pelos alunos nas categorias da questão 4 (b).

Questão 5 - Jussara ganha 15\% a mais que João. No mês de março Joana será promovida e receberá um aumento de $20 \%$. Considerando o novo salário de Jussara, quantos por cento ela ganhará a mais que João?

A tabela 8 indica que o número de acertos no pós-teste aumentou em $150 \%$.

Tangram - Revista de Educação Matemática, Dourados - MS - v.2 n. 2, pp. 25 - 46 (2019) 


\section{Aprimorando o desempenho de futuros profissionais em matemática financeira}

Tabela 8-Tabela com o quantitativo de respostas por categoria apresentadas à questão 5 .

\begin{tabular}{|l|l|c|c|}
\hline & Descrição & Série l & Série 2 \\
\hline I & Efetuou a soma das porcentagens 20\%+15\%=35\%. & 11 & 9 \\
\hline II & Efetuou a multiplicação 0,15.1,2=0,18 $\rightarrow 18 \%$. & 1 & 1 \\
\hline III & Estipulou valores errando o cálculo. & 3 & 1 \\
\hline IV & Em branco. & 5 & 3 \\
\hline V & Acertou a questão, respondendo 38\%. & 4 & 10 \\
\hline \multicolumn{2}{|c|}{ Total } & $\mathbf{2 4}$ & $\mathbf{2 4}$ \\
\hline
\end{tabular}

Novamente, observa-se a que os erros motivados pela aplicação equivocada de aumento e desconto sucessivos como a maior dificuldade na $1^{\mathrm{a}}$ aplicação, migrando, praticamente, para acertos na $2^{a}$ aplicação. Uma resposta correta poderia ser encontrada representando o salário de João por S, e o de Jussara por 1,15 S. Com o aumento, o salário de Jussara ficará multiplicado por 1,20, o que resulta em 1,2 x 1,15 S = 1,38 S. Portanto, Jussara passará a ganhar 38\% a mais eu João.

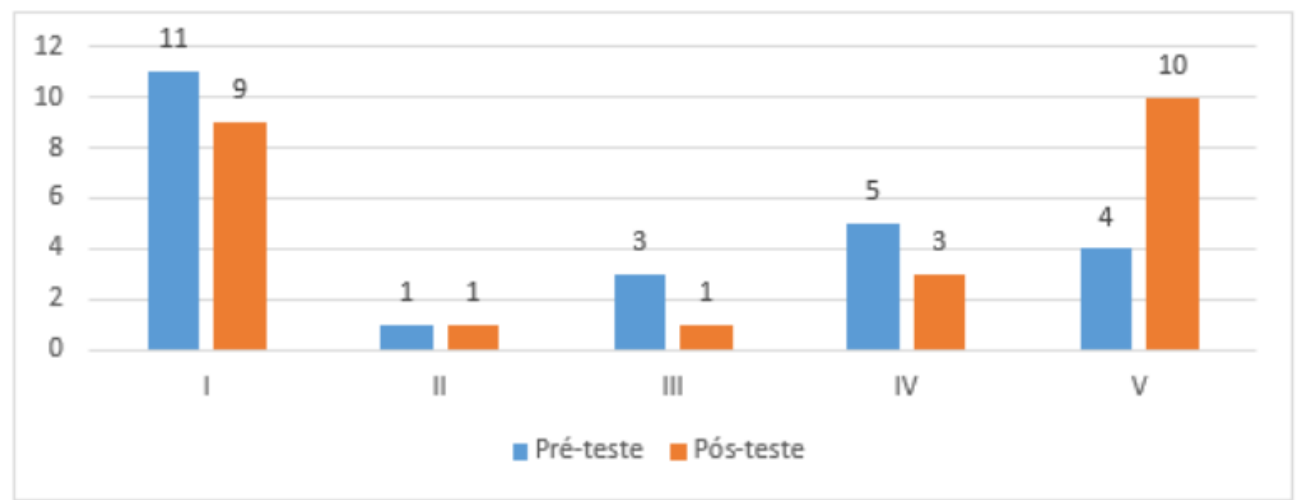

Gráfico 8-Concentração de respostas apresentadas pelos alunos nas categorias da questão 5 .

Apesar de o equívoco de somar os índices de aumentos sucessivos ter sido amplamente discutido em sala de aula com a resolução de questões práticas, observa-se que mais de um terço da amostra (9 alunos) continuaram persistindo no erro de tipo I.

\section{Considerações Finais}

A heterogeneidade da turma foi um elemento determinístico para o desenvolvimento das aulas. O fato de possuirmos alunos em diferentes níveis de conhecimento exigia que as aulas ocorressem em um nível mais lento para que pudéssemos tentar resgatar aqueles alunos com maior dificuldade.

A necessidade de se cumprir a ementa da disciplina impedia que se permanecesse por mais tempo em um determinado assunto, até que todas as dúvidas fossem extintas. Talvez um programa

Tangram - Revista de Educação Matemática, Dourados - MS - v.2 n. 2, pp. 25 - 46 (2019) 


\section{Aprimorando o desempenho de futuros profissionais em matemática financeira}

de monitoria pudesse auxiliar nessa problemática, com o que não contávamos na instituição em questão.

A abordagem utilizada com problemas práticos, sem dúvida, foi de agrado do grupo, contribuindo para a sua formação profissional.

No início, a utilização do eixo das setas foi amplamente rejeitada, o que é compreensível, já que o aluno espera que a regra de três resolva todos os problemas de Matemática Financeira. Essa crença é até válida em situações simples, enquanto o período de tempo utilizado nas resoluções é pequeno. A partir do momento em que os exercícios demandavam tempos de financiamentos mais longos, os estudantes passaram a perceber as dificuldades, e querer utilizar o eixo das setas. Entretanto, como deixaram de usá-lo no momento inicial de resolução das situações propostas, quando poderiam aprender a utilizar essa estratégia de resolução, tiveram que fazê-lo com menor tempo. Sugerimos aqui a necessidade de se incentivar a sua utilização a partir dos primeiros exercícios, mesmo para as questões mais simples.

Atualmente é comum falarmos que nossos alunos são imediatistas, e são, na nossa concepção. Ora, eles são da era tecnológica. Querem fazer diferentes atividades, simultaneamente, que, em muitas vezes, resultam em respostas rápidas, imediatas. Dessa forma, em nossas aulas, nos deparamos com alunos que não possuem paciência para esperar o resultado, ouvir a explicação adequada, entender o processo de obtenção desse resultado, etc.

Nesse contexto, a experiência da resolução de problemas com a utilização do eixo das setas permitiu que o aluno pudesse desenvolver um raciocínio de resolução das questões fornecidas, tendo em vista que se preconiza a não memorização de fórmulas e, sim, a visualização do processo de resolução. Por isso, a metodologia é prática e visual. Dessa forma, pudemos observar que alguns alunos com deficiências de conceitos matemáticos da Escola Básica, ao final do período, demonstraram grande evolução na resolução de problemas que envolviam o cálculo de juros e do pagamento parcelado através da utilização do eixo das setas.

Os percentuais comparativos entre o pré-teste e o pós-teste indicam avanços significativos. Os índices de questões deixadas em branco foram reduzidos em $45 \%$. Além disso, alguns tipos de erro não foram registrados no pós-teste.

Acreditamos que os resultados sugerem que a abordagem é válida, tendo em vista o perfil da turma onde foi desenvolvido esse trabalho.

\section{Referências}

CURY, H. (2007). Análise de erros: o que podemos aprender com os erros dos alunos. Belo Horizonte, MG: Autêntica Editora,.

Tangram - Revista de Educação Matemática, Dourados - MS - v.2 n. 2, pp. 25 - 46 (2019) 
CURY, H. e. (2004). Análise de erros em Cálculo: uma pesquisa para embasar mudanças. Em Volume 6 (pp. n.1, p. 27-36,). Acta Scientiae.

D’AMBRÓSIO, B. S., \& LOPES, C. (2015). Vertentes da subversão na produção científica em Educação Matemática. Campinas-SP: Mercado de Letras.

FIORENTINI, D. e. (2009). Investigação em Educação Matemática: percursos teóricos e metodológicos. . Campinas: Autores Associados.

MEC. (1998). Ministério de Educação, Cultura e Lazer: Parâmetros Curriculares Nacional. Brasilia.

MEC. (28 de Maio de 2018). Base Nacional comum para o Ensino Médio. Fonte: BNCC : /basenacionalcomum.mec.gov.br/wpcontent/uploads/2018/04/BNCC_EnsinoMedio_embaixa_site.pdf

MEC. (2018). Ministério de educação, Cultura e Lazer: Base Nacional Comum. Brasilia .

NASSER, L. (2009). À vista ou a prazo sem juros: qual dessas modalidades de pagamento é mais vantajosa? Em Educação Matemática em Revista-RS (pp. v.2, pp. 93-99). Canoas-RS: SBEM-RS.

NASSER, L. (2010). Matemática Financeira na Escola Básica: uma abordagem prática e visual. RJ: Projeto Fundão IM-UFRJ.

NOVAES, R. C. (2009). Uma abordagem visual para o ensino de Matemática Financeira no Ensino Médio. . Dissertação de mestrado. UFRJ, RJ, Brasil .

PINTO, M. A. (2011). A importância da Matemática Financeira na formação de professores. Monografia de final de curso de Licenciatura. IM-UFRJ, Rio de Janeiro, Brasil.

QUEIROZ, M. R., \& BARBOSA, J. (2015). Exercícios de Livros Didáticos de Matemática Financeira e suas Fronteiras com Situações do Cotidiano e de Ambientes de Trabalho. Anais VI SIPEM. Pirenópolis, GO.

Resultado do PISA (volume IV), Students 'Financial Literacy. (2015). Fonte: OCDE: http://www.oecd.org/pisa/pisa-2015-results-volume

SÁ, I. P. (2009). Duas vezes 100 é igual a 200? . Revista do Professor de Matemática SBM, pp. p.13-16.

SEE-RJ. (2006). Secretaria de Estado de Educação do Rio de Janeiro. Reorientação Curricular,. RJ.

SOUSA, G., NASSER, L., TORRACA, M., \& ASSEMANY, D. (29 de MAIO de 2018). Educação Financeira Prática e Visual. Fonte: cibem7.semur.edu.uy/7/actas/pdfs/846.pdf

SOUSA, G., TORRACA, M., NASSER, L., \& PEREIRA, J. (2008). Capacitando professores para o ensino de Matemática Financeira. . UniRio-RJ: SBEM-RJ.

ZOT, W. D. (2006). Matemática Financeira. Porto Alegre, RS: Ed. da UFRGS.

Enviado:27/09/2018

Aceite: $10 / 12 / 2018$

Tangram - Revista de Educação Matemática, Dourados - MS - v.2 n. 2, pp. 25 - 46 (2019) 